\title{
RIEGO DE UN CULTIVO DE CITRICOS CON AGUA MARINA DESALINIZADA. RESULTADOS PRELIMINARES EN SUELO Y PLANTA
}

Navarro, J.M. ${ }^{1}$, Robles, J.M. ${ }^{1}$, Antolinos, V. ${ }^{1}$, Botía, P. ${ }^{1}$, Hernández, F.M. ${ }^{1}$, Olivares, L. ${ }^{1}$, Arques, E. ${ }^{1}$, MaestreValero, J.F.2 Martínez-Alvarez, V. ${ }^{2}$, Jodar, F.J.2 ${ }^{2}$ Acosta-Avilés J.A.2, Pérez-Pérez, J.G.1,3

1 IMIDA, C/Mayor s/n, Murcia 30150, Spain josefam.navarro2@carm.es

2 UPCT, Paseo Alfonso XIII, Cartagena, 48. 30203, Spain

${ }^{3}$ IVIA, CV-315 km 10.7, Moncada, 46113, Spain

Introducción

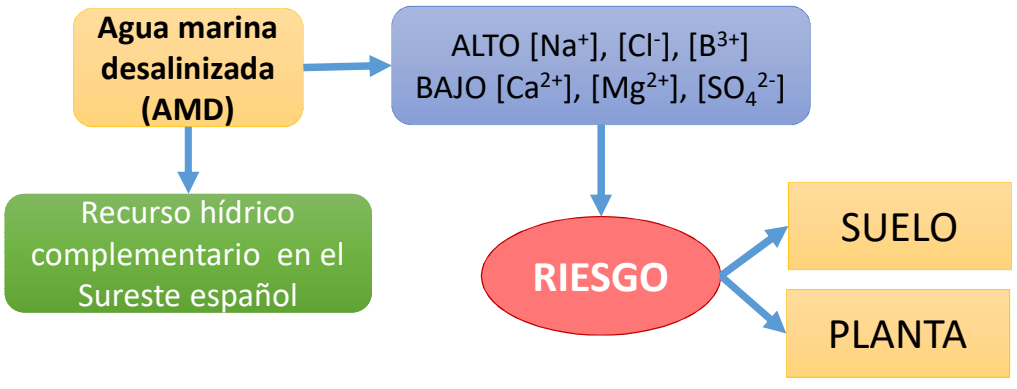

Objetivo

Promover la sostenibilidad agronómica del AMD, minimizando los riesgos de fitotoxicidad por $\mathrm{Cl}^{-}, \mathrm{Na}^{+} \circ \mathrm{B}^{3+}$ y de sodificación de suelos

Evaluación del impacto sobre el suelo y la planta en un cultivo de cítricos, caracterizado por su sensibilidad a las características físico-químicas del AMD

\section{Material y Métodos}

Riego (20 meses)

Agua de la Comunidad de Regantes del Campo de Cartagena (CR)

Parcela experimental de árboles jóvenes de mandarino 'Safor'
Agua AMD de la desaladora de Escombreras (AMD)

Agua mezcla $50 \% \mathrm{CR}+50 \% \mathrm{AMD}$

(AM)

Análisis

periódicos

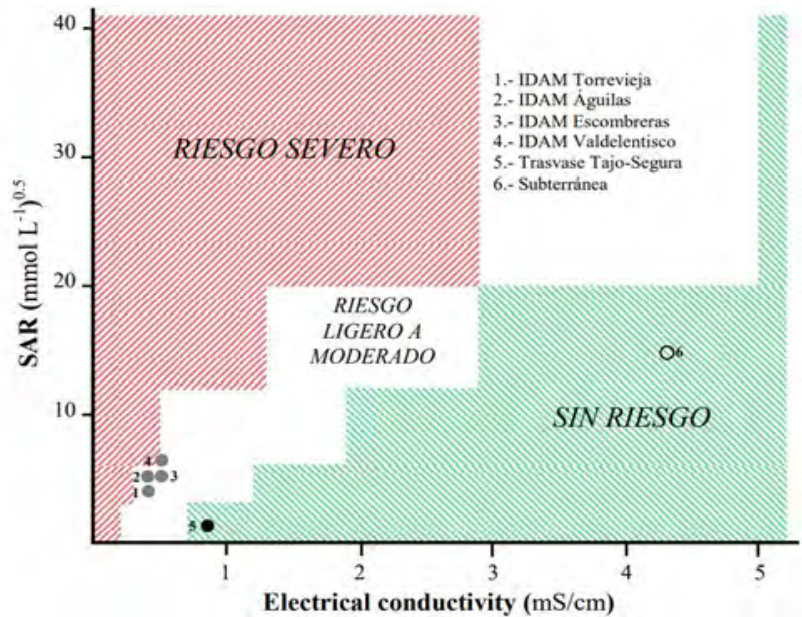

Riesgo de alcalinización del suelo por el riego con agua marina desalinizada de cuatro plantas desalinizadoras del sureste de España, junto a la de otros suministros convencionales (trasvase Tajo-Segura y agua subterránea del Campo de Cartagena)

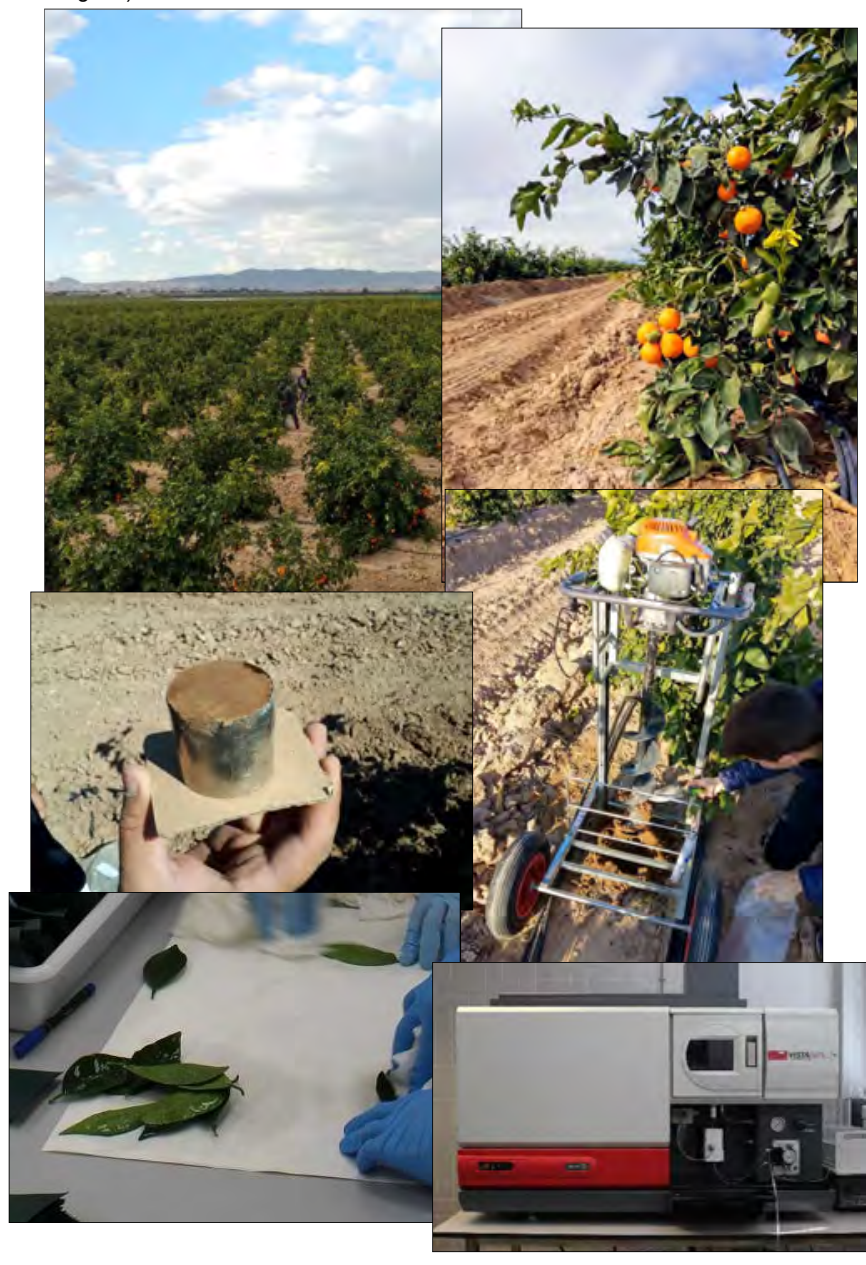

\section{PLANTA}

$\mathrm{pH}, \mathrm{CE}, \mathrm{SAR}$,

$\mathrm{Na}^{+}, \mathrm{Ca}^{2+}, \mathrm{Mg}^{2+}, \mathrm{B}^{3+}, \mathrm{Cl}^{-} \mathrm{Na}^{+}, \mathrm{Ca}^{2+}, \mathrm{Mg}^{2+}, \mathrm{B}^{3+}, \mathrm{Cl}^{-}$
Este trabajo ha sido financiado por el Fondo Europeo de Desarrollo Regional (FEDER) y el Ministerio de Ciencia, Innovación y Universidades - Agencia Estatal de Investigación a través de los proyectos SEARRISOST (RTC-2017-6192-2) y RIDESOST (AGL2017-85857) 